\title{
The status of the genus Pelczaria (Poston 1994) and the species Pelczaria aurantia (Poston 1994). Request for an Opinion
}

\author{
B. J. Tindall, Peter Schumann and Erko Stackebrandt
}

Author for correspondence: B. J. Tindall. Tel: +495312616 352. Fax: +495312616418. e-mail: bti@dsmz.de

DSMZ - Deutsche Sammlung von

Mikroorganismen und Zellkulturen $\mathrm{GmbH}$, Mascheroder Weg $1 \mathrm{~b}$, D-38124 Braunschweig, Germany

\begin{abstract}
Based upon the results of another publication [P. Schumann et al. (2000). Int J Syst Evol Microbiol 50, 1421-1424) it is concluded that the culture Pelczaria aurantia ATCC $49321^{\top}$ ( = DSM 12801') currently being distributed does not conform to the description of the type strain of Pelczaria aurantia (Poston 1994) and the type species of the genus Pelczaria (Poston 1994). It is proposed that the Judicial Commission consider (1) that the organism currently deposited as ATCC $49321^{\top}$ and DSM $12801^{\top}$ be recognized as a member of the species Kocuria rosea; (2) that the organism deposited as ATCC $49321^{\mathrm{T}}$ and DSM $12801^{\top}$ as the type strain of the species does not represent a strain of the species Pelczaria aurantia; (3) to place the name Pelczaria aurantia (Poston 1994) on the list of rejected names if a suitable replacement strain, or a neotype, cannot be found within 2 years of publication of this Request (Rule 18c); (4) to place the genus name Pelczaria (Poston 1994) on the list of rejected names [c.f. Recommendation $20 d$ (3)] if a suitable replacement type strain or a neotype for the type species of the genus Pelczaria (Poston 1994) cannot be found as outlined in (3).
\end{abstract}

Keywords: Pelczaria aurantia, Kocuria rosea, Request for an Opinion
In a previous article it has been shown that Pelczaria aurantia ATCC $49321^{\mathrm{T}}\left(=\operatorname{DSM} 12801^{\mathrm{T}}\right)$ and the type strain of the species Kocuria rosea (basonym: Micrococcus roseus), DSM $20447^{\mathrm{T}}$, belong to the same species. Under normal circumstances application of the Rules of the Bacteriological Code (1990 Revision) (Lapage et al., 1992) would mean that the two species should be united in one genus, and in the same species. This would mean that Pelczaria aurantia (Poston 1994) and Kocuria rosea [(Flügge 1886), Stackebrandt et al. 1995] are subjective synonyms. Both species are the type species of the respective genera, so that Rules 42 and 15 could be applied, which would make the senior subjective synonym for the unified genera Pelczaria, and Pelczaria aurantia would be the senior subjective synonym of the unified species.

However, we have presented evidence in a previous publication (Schumann et al., 2000) which indicates that there are problems associated with the data which we have collected on Pelczaria aurantia (ATCC 49321 ${ }^{\mathrm{T}}$ $=$ DSM $12801^{\mathrm{T}}$ ) and that published by Poston (1993). In particular:

(i) The DNA-DNA hybridization studies by Poston (1993) indicate that Pelczaria aurantia and Kocuria rosea (ATCC $186^{\mathrm{T}}$ ) are $<5 \%$, whereas our data gives values of $87 \cdot 1 \%$ between Pelczaria aurantia (ATCC $49321^{\mathrm{T}}$ ) and Kocuria rosea $\left(\right.$ DSM $\left.20447^{\mathrm{T}}\right)$.

(ii) The DNA-RNA hybridization study of Poston (1993) indicates that there was no significant hybridization between Pelczaria aurantia and Kocuria rosea (ATCC $186^{\mathrm{T}}$ ), or any of the other species tested. The homologous hybridization value of Pelczaria aurantia with itself was $100 \%$, providing an internal control within the experiments. Our data indicates that the 16S rDNA sequences of Pelczaria aurantia (ATCC $\left.49321^{\mathrm{T}}=\mathrm{DSM} 12801^{\mathrm{T}}\right)$ and Kocuria rosea (DSM $20447^{\mathrm{T}}$ ) are identical, which would mean, by extrapolation, that the DNA-RNA hybridization values between Pelczaria aurantia and Kocuria rosea (ATCC $186^{\mathrm{T}}$ ) should be $100 \%$, or close to $100 \%$.

(iii) The cell wall composition reported for Pelczaria aurantia is Glu-Ser-His-Lys-Ala (1:1:1:1:8) (Poston, 1993), whereas our results indicate that the composition is Glu-Lys-Ala $(1: 1 \cdot 5: 3 \cdot 4)$, typical for members of the species Kocuria rosea.

(iv) The phospholipid composition reported for Pelczaria aurantia is PG, PC, and PE (Poston, 1993), 
whereas the lipid composition of Pelczaria aurantia ATCC $49321^{\mathrm{T}}\left(=\mathrm{DSM} 12801^{\mathrm{T}}\right)$ and Kocuria rosea $\left(\right.$ DSM $\left.20447^{\mathrm{T}}\right)$, reported by Schumann et al. $(2000)$, is identical and comprises PG, DPG, an unknown phospholipid and a glycolipid.

(v) The $\mathrm{G}+\mathrm{C}$ content of the DNA for Pelczaria aurantia, given by Poston (1993), is $59 \mathrm{~mol} \%$ (HPLC) and $60 \mathrm{~mol} \%\left(T_{\mathrm{m}}\right)$, whereas the data of Schumann et al. (2000) gives a value of $72 \mathrm{~mol} \%$ (HPLC), which is within the range given for members of the species Kocuria rosea.

We have taken steps to check the identity of Pelczaria aurantia deposited in the ATCC under the number ATCC $49321^{\mathrm{T}}\left(=\mathrm{DSM} 12801^{\mathrm{T}}\right)$, against a subculture of the strain held by the NIH, Bethesda, MA, USA, both obtained from the original depositor, and both of which are identical in our studies, but clearly different from the properties described by Poston (1993). Based on the data we have presented, we conclude that the organism currently deposited in the ATCC as ATCC 49321, in the DSMZ as DSM 12801, and that held by the NIH is, in fact, a member of the species Kocuria rosea. Furthermore, we conclude that the organism originally described by Poston (1993) as the type strain of the type species of Pelczaria aurantia was, based on the DNA-DNA hybridization data, DNA-RNA hybridization data, cell wall analysis, and polar lipid analysis, neither a member of the species Kocuria rosea, nor was it a member of the genus Kocuria. We, therefore, conclude that the culture currently being distributed does not conform to the description of the type strain of Pelczaria aurantia (Poston 1994) and type species of the genus Pelczaria (Poston 1994). Consequently we are referring this matter to the Judicial Commission (Rule 18g) and propose that the Judicial Commission consider the following course of action.

(1) The organism currently deposited as ATCC $49321^{\mathrm{T}}$ and DSM $12801^{\mathrm{T}}$ be considered to be members of the genus Kocuria (Stackebrandt et al. 1995), and should be recognized as a member of the species Kocuria rosea [(Flügge 1886) Stackebrandt et al. 1995].

(2) The data currently available for ATCC $49321^{\mathrm{T}}$ and DSM $12801^{\mathrm{T}}$ is significantly different from that published by Poston (1993). The circumscription of the genus Pelczaria (Poston 1994) and the species Pelczaria aurantia (Poston 1994) indicates that the organism deposited as ATCC $49321^{\mathrm{T}}$ and DSM $12801^{\mathrm{T}}$, as the type strain of the species, does not represent a strain of the species Pelczaria aurantia (Poston 1994).

(3) Based on our findings a strain which conforms to the original description of the species Pelczaria aurantia (Poston 1994) is not currently available. The species is, therefore, not represented by a type strain which conforms to the circumscription of the taxon. We, therefore, propose that a search be made for a suitable replacement type strain, or a neotype should be designated according to Rule $18 \mathrm{c}$. We suggest that if a suitable replacement strain, or a neotype, cannot be found within 2 years of publication of this Request, that the Judicial Commission place the name Pelczaria aurantia (Poston 1994) on the list of rejected names.

(4) The type species of the genus Pelczaria (Poston 1994) is Pelczaria aurantia (Poston 1994), which is currently not represented by a type strain which conforms to the circumscription of the species [c.f. Recommendation 20d (3)]. If a suitable replacement type strain or a neotype for the species cannot be found as outlined in (3), we suggest that, with the placement of the species name Pelczaria aurantia (Poston 1994) on the list of rejected names by the Judicial Commission, the Judicial Commission should also place the genus name Pelczaria (Poston 1994) on the list of rejected names.

\section{References}

Flügge, C. (1896). Die Mikroorganismen, pp. 1-692. Leipzig: F. C. W. Vogel.

Lapage, S. P., Sneath, P. H. A., Lessel, E. F., Skerman, V. B. D., Seeliger, H. P. R. \& Clark, W. A. (editors) (1992). International Code of Nomenclature of Bacteria (1990 Revision). Bacteriological Code. Washington, DC: American Society for Microbiology.

Poston, J. M. (1993). Pelczaria aurantia gen. nov., sp. nov., a newly described orange-colored bacterium. Arch Microbiol 140, 114-120.

Poston, J. M. (1994). Pelczaria aurantia gen. nov., sp. nov. In Validation of the Publication of New Names and New Combinations Previously Effectively Published Outside the IJSB, List no. 48. Int J Syst Bacteriol 44, 182-183.

Schumann, P., Tindall, B. J., Mendrock, U., Kramer, I. \& Stackebrandt, E. (2000). Pelczaria aurantia ATCC $49231^{\mathrm{T}}(=$ DSM $12801^{\mathrm{T}}$ ) is a strain of Kocuria rosea (Stackebrandt et al. 1995). Int J Syst Evol Microbiol 50, 1421-1424.

Stackebrandt, E., Koch, C., Gvozdiak, O. \& Schumann, P. (1995). Taxonomic dissection of the genus Micrococcus: Kocuria gen. nov., Nesterenkonia gen. nov., Kytococcus gen. nov, Dermacoccus gen. nov., and Micrococcus Cohn 1872 gen. emend. Int J Syst Bacteriol 45, 682-892. 